\title{
Impact of prehospital mobile intensive care unit intervention on mortality of septic patients
}

\author{
Romain Jouffroy ${ }^{\# *}$, Anastasia Saade ${ }^{\#}$, Pascal Philippe, Pierre Carli and Benoît Vivien \\ Department of Anesthesia \& Intensive Care Unit, SAMU, Hôpital Necker - Enfants Malades 149 rue de Sèvres 75015 Paris, University Paris Descartes, France \\ "contributed equally to the manuscript
}

\begin{abstract}
Background: The outcome of sepsis relies on the early diagnosis and implementation of appropriate treatments. For the management of out-of-hospital sepsis patients, prehospital emergency services, named SAMU in France dispatch to the scene an emergency mobile team (EMT) or a prehospital mobile intensive care unit (MICU) based on the patient's severity. Patients are therefore admitted to the emergency department (ED) or to the intensive care unit (ICU). The impact of prehospital MICU intervention on patient's prognosis remains unclear.

The aim of this study was to describe the impact of prehospital MICU intervention on mortality at day 28 (D28) of sepsis patients.

Methods: We performed a retrospective study on sepsis patients managed by prehospital teams, MICU or EMT, before admission to the ED or ICU. The primary outcome was mortality at D28.

Results: During the study period, 30,642 calls were received by the SAMU, 140 concerned patients with suspected sepsis. The suspected origin of sepsis was mainly pulmonary for $78(55 \%)$ patients. Forty-five (32\%) patients had a qSOFA $\geq 2$. Thirteen (9\%) patients deceased at D28, 12 in ED and 1 in the ICU. Of these, 2 patients were admitted to the hospital by a MICU. After adjusting for confounding factors, the relative risk of mortality at D28 for sepsis patients admitted to the hospital by a MICU was 0.40 .

Conclusion: We describe an association between prehospital MICU intervention and mortality at D28 of patients with sepsis. Prehospital MICU intervention for out-of-hospital sepsis patients is associated with $60 \%$ reduced mortality at D28. Larger studies are needed to confirm the impact of the intervention of prehospital MICU on mortality of septic patients.
\end{abstract}

\section{Introduction}

Septic shock concerns around 19 million people worldwide annually [1,2], generating 180000 deaths in the United States of America [3]. The in-hospital mortality rate related to septic shock still reaches $30 \%$ at day $28[2,4]$ despite continuous guidelines to improve the management of these patients within the last two decades [5]. It is now clearly admitted that outcome relies on the early identification of sepsis patients at high risk of poor outcome to initiate rapid implementation of appropriate treatments, especially hemodynamic optimization and antibiotic administration [6-8]. For out-of-hospital patients, sepsis has to be diagnosed as early as possible starting in the prehospital setting.

In France, the management of out-of-hospital emergencies is based on the emergency medical services called SAMU for "service d'aide médicale d'urgence". The SAMU is reached via a national access call number, the number 15 [9]. For patients requiring hospital admission, an emergency mobile team (EMT), a regular ambulance or a prehospital mobile intensive care unit (MICU) is dispatched to the scene. While an EMT always transfers patients to the emergency department (ED), patients transported by a MICU might be admitted to the ED or to the intensive care unit (ICU) according to their severity. Efficient prehospital triage is thus crucial to enable appropriate orientation of patients. However, relevant tools to diagnose sepsis and to evaluate patients' severity lack in this context. Actually, studies reported the lack of efficiency of the quick sepsis-related organ dysfunction assessment score (qSOFA) in the prehospital setting to predict ICU admission
[10-14]. Consequently, in this context, evaluation of patients remains complex. Further efforts are needed to improve early triage of septic patients in this environment. Positive impact of early specialised management of patients by prehospital MICU intervention was shown for cardiac arrest and severe trauma [9]. In the case of sepsis, the purpose of early management of patients by a MICU hasn't been evaluated yet.

The aim of this study was to describe the impact of prehospital mobile intensive care unit intervention on mortality at day 28 of sepsis patients.

\section{Methods}

\section{Population and data}

Patients with suspected sepsis cared for by the SAMU of Paris (SAMU 75) between April $1^{\text {st }}$ and May 31 $31^{\text {st }}, 2011$ were included in the study. Patients under 18, pregnant women and patients with incomplete data sets were excluded.

${ }^{*}$ Correspondence to: Romain Jouffroy, Department of Anesthesia \& Intensive Care Unit, SAMU, Hôpital Necker Enfants Malades 149 rue de Sèvres 75015 Paris, University Paris Descartes, France, E-mail: romain.jouffroy@gmail.com

Key words: sepsis, mobile intensive care unit, prehospital setting, mortality

Received: May 27, 2018; Accepted: June 07, 2018; Published: June 11, 2018 
Sepsis was suspected in case of fever $\geq 38.0^{\circ} \mathrm{C}$ during one hour or $38.3^{\circ} \mathrm{C}$ once or hypothermia $<36^{\circ} \mathrm{C}$ with a medical history compatible with an infection $[15,16]$. The site of infection was suspected according to the patient medical history and clinical signs.

Data including patient's demographic characteristics, and clinical evaluation (systolic, diastolic and mean blood pressure (SBP, DBP and $\mathrm{MBP})$, heart rate (HR), respiratory rate (RR), temperature and Glasgow coma scale (GCS), pulse oximetry) were retrieved from recorded phone calls made during prehospital care delivery and from the SAMU prehospital medical files. The primary outcome was mortality at day 28 and was collected from hospital reports.

In order to minimize the bias associated with data abstraction, data collection was perform by a single investigator using a standardized abstraction template, defined prior to data collection [17].

Immunocompromised status was retained if one or more of the following items were present in the patient's past medical history: diabetes mellitus, chronic renal insufficiency, corticosteroids or another immunosuppressive treatment, infection by human immunodeficiency virus and/or $\mathrm{C}$ viral hepatitis.

Assessment of the prehospital qSOFA score was based on the three following clinical features: systolic blood pressure $\leq 100 \mathrm{mmHg}$, respiratory rate $\geq 22 / \mathrm{min}$ and altered mental status determined by a Glasgow Coma Scale $(\mathrm{GCS})<15$, with one point awarded for each item.

In keeping with the French legislation, our local ethical committee (Comité de Protection des Personnes, Ile de France, Paris) considered that consent of patients was waived for participation in this observational study.

\section{Study design and setting}

The SAMU is composed of switchboard operators and physicians who determine, over the phone, the appropriate level of care to dispatch to the scene. The decision-making is based on the patient's medical history and symptoms, related by the patient himself, his relatives, or any witness.

For life-threatening emergencies, the "Service Mobile d'Urgence et de Réanimation" (SMUR), corresponding to a prehospital mobile intensive care unit (MICU), enables direct admission to the ICU or to the ED [18]. The MICU is composed of a driver, a nurse, and an emergency physician and is equipped with medical devices and drugs allowing initial management of main organs deficiency [9]. In the case of sepsis, the MICU is able to initiate hemodynamic optimization (fluid expansion and/or catecholamine infusion) and antibiotherapy. For less severe cases, an emergency mobile team (EMT) (fire-fighters) or an ambulance, corresponding to a paramedic team, is dispatched to the scene.

After arrival to the scene of the appropriate care support, EMT or MICU, the patient's demographic characteristics, and clinical evaluation (systolic, diastolic and mean blood pressure (SBP, DBP and $\mathrm{MBP})$, heart rate (HR), respiratory rate (RR), body temperature and Glasgow coma scale (GCS), pulse oximetry) are communicated to the regulation call centre to decide on the best course of action. Thereafter, patients are either transferred to the ED or to the ICU.

\section{Statistical Analysis}

Univariate and multivariable analyses were conducted to evaluate the relationship between all covariates and mortality at day 28 .
A propensity score analysis, including age $>80$ years, immunocompromised status and qSOFA $\geq 2$, was used to reduce the effect of confounders (19). Age $>80$ years, immunocompromised status and $\mathrm{qSOFA} \geq 2$ were reported to be associated with increased mortality in septic patients [20-22].

The covariate balancing propensity score method was used to allow simultaneous optimization of the prediction of the outcome and the covariate balance. As $\mathrm{p}$ value is influenced by the sample size, standardized mean difference (SMD) was used to evaluate imbalance matching using the following formulae, described by Austin [23] :

$$
S M D=100 * \frac{X(\text { cases })-X(\text { controls })}{\sqrt{\frac{S^{2}(\text { cases })+S^{2}(\text { controls })}{2}}}
$$

Where $\mathrm{x}$ corresponds to the mean or proportion for binary variables and classes of categorical variables and $s$ the variance.

Cases correspond to patients admitted to the ED or to the ICU by a MICU, and controls to patients admitted to the ED by an EMT. In the matched sample, baseline characteristics between cases and controls for mortality at day 28 were compared using an unpaired t test. All $\mathrm{p}$ values were two-tailed and $\mathrm{p}<0.05$ was considered significant.

At least, the relative risk (RR) was used to evaluate patients' mortality at day 28 transported by a MICU or an EMT.

Data are expressed as mean \pm standard variation (SD) for Gaussian variables, or median with 1st quartile and 3rd quartile for non-normal variables, or number and percentage.

All analyses were performed using R 3.4.2 (http://www.R-project. org; the R Foundation for Statistical Computing, Vienna, Austria).

\section{Results}

During the study period, 30,642 calls were received by the SAMU 75 call centre. One hundred forty calls concerned patients with suspected sepsis (Figure 1).

Seventy-six (54\%) patients were male, and the median age was 72 years (43-81) (Table 1). Forty (29\%) patients were older than 80 years. Eighty-six (61\%) patients were immunocompromised.

The predominant sites of infection were pulmonary for 77 (55\%) patients, urinary for 20 (14\%) patients and abdominal for 19 (13\%) patients.

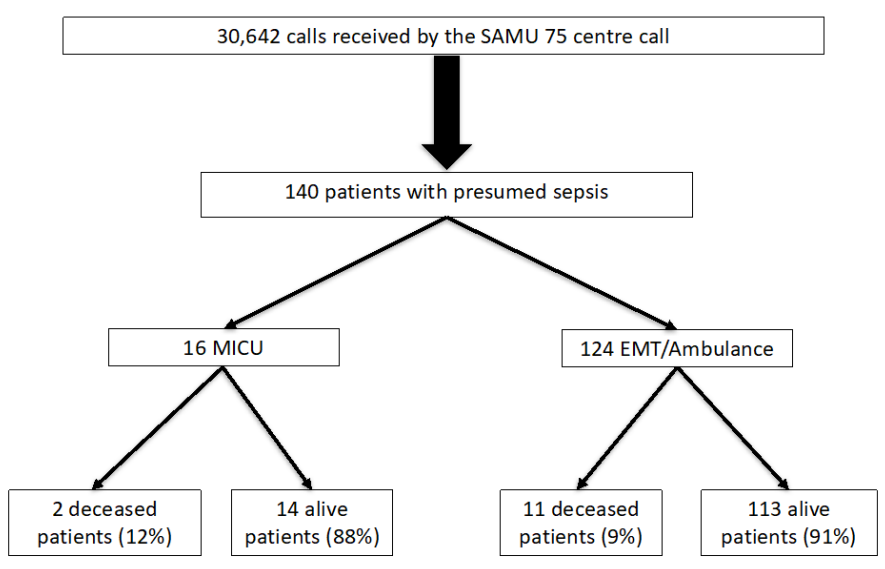

Figure 1. Flow chart. SAMU: Service d'aide médicale d'urgence, qSOFA: quick sepsisrelated organ dysfunction assessment score, ICU: intensive care unit; ED: emergency department. MICU: mobile intensive care unit, EMT: emergency mobile team. 
Table 1. Demographic and clinical characteristics of patients with sepsis admitted to the hospital by a MICU or an EMT. Quantitative variables are expressed as median [ $1^{\text {st }}$ quartile- $3^{\text {rd }}$ quartile]. Qualitative variables are expressed as absolute value and percentage.

\begin{tabular}{|c|c|c|c|}
\hline & Alive at day $28(n=127)$ & $\begin{array}{l}\text { Deceased at day } 28 \\
(n=13)\end{array}$ & $\begin{array}{l}\text { Overall population } \\
(\mathrm{n}=140)\end{array}$ \\
\hline Age (years) & $70[39-81]$ & $78[66-87]$ & $72[43-81]$ \\
\hline Age $>80$ years & $36(90 \%)$ & $4(10 \%)$ & $40(29 \%)$ \\
\hline Male gender & $67(52 \%)$ & $9(69 \%)$ & $76(54 \%)$ \\
\hline Immunosuppression & $77(61 \%)$ & $9(69 \%)$ & $86(61 \%)$ \\
\hline Systolic blood pressure $(\mathrm{mmHg})$ & $120[96-138]$ & $101[95-110]$ & $110[96-130]$ \\
\hline Diastolic blood pressure $(\mathrm{mmHg})$ & $70[50-80]$ & $60[50-70]$ & $70[50-80]$ \\
\hline Mean blood pressure $(\mathrm{mmHg})$ & 87 [63-100] & $73[65-83]$ & 83 [63-100] \\
\hline Heart rate (beats/min) & $108[97-120]$ & $101[81-130]$ & 107 [96-120] \\
\hline Pulse oximetry (\%) & 96 [90-98] & $93[90-96]$ & 96 [90-98] \\
\hline Respiratory rate (moves/min) & $24[22-28]$ & $26[24-30]$ & $25[22-28]$ \\
\hline GCS & $15[15-15]$ & $15[15-15]$ & $15[15-15]$ \\
\hline Body temperature $\left({ }^{\circ} \mathrm{C}\right)$ & $38.7[37.9-39.0]$ & $38.5[37.0-39.0]$ & $38.6[37.9-39.0]$ \\
\hline Prehospital management by MICU & $14(11 \%)$ & $2(15 \%)$ & $16(11 \%)$ \\
\hline Patients admitted in the ED & $112(95 \%)$ & $6(5 \%)$ & $118(84 \%)$ \\
\hline Patients admitted in the ICU & $15(68 \%)$ & $7(32 \%)$ & $22(16 \%)$ \\
\hline qSOFA $>2$ & $39(31 \%)$ & $7(54 \%)$ & $45(32 \%)$ \\
\hline
\end{tabular}

GCS: Glasgow coma scale, qSOFA: quick sepsis-related organ dysfunction assessment score, MICU: mobile intensive care unit, ED=emergency department, ICU=intensive care unit.

In the prehospital setting, median temperature was $38.6^{\circ} \mathrm{C}(37.9-$ 39.0), median SBP was $110 \mathrm{mmHg}$ [96-130], and median RR was 25/ min [22-28]. Forty-five (32\%) patients had a qSOFA $\geq 2$. All patients had a GCS of 15.

Among the 140 patients with suspected sepsis in the prehospital setting, $16(11 \%)$ patients were transferred to the hospital by a MICU. None of them received antibiotics prior to hospital admission. Thirteen (9\%) patients died at day 28, 12 had been admitted to the ED and one to the ICU and 2 had been transported by a MICU. Among the 2 deceased patients transported by a MICU, one had been admitted to the ED and one to the ICU.

All deaths were related to a documented history of sepsis. A microbiological documentation was obtained in $42 \%$ of the cases and was pulmonary for $38(65 \%)$ patients (Table 2).

In the univariate analysis, no variable was significantly associated with death occurrence at day 28 (Table 3). No variables included in the propensity score significantly differed between the cases and the controls after propensity score matching (Figure 2 and Table 4).

After adjusting for confounding factors, the relative risk (RR) of mortality at day 28 concerning patients with presumed sepsis admitted to the hospital by a MICU, reached 0.40 , while the RR was 2.5 for those admitted to the hospital by an EMT.

\section{Discussion}

In this work, we report an association between mortality at day 28 and the intervention of a MICU for sepsis patients cared for in the prehospital setting. The intervention of a prehospital MICU is associated with $60 \%$ reduced mortality at day $28(\mathrm{RR}=0.4)$. This work is the first study to investigate the role of prehospital transportation in the prognosis of septic patients. Inter-hospital transportation of critically ill patients by a MICU was widely described showing clinical stability based on the SOFA score [24]. On the contrary, prehospital transportation raises other issues, as the level of emergency has to be first identified by the dispatch centre. Actually, a significant proportion of patients are transported by an inappropriate mode of transport. Half of out-of-hospital sepsis patients are transported by non-EMS [25]. The relationship with mortality is controversial as some found
Table 2. Presumed site of infection in sepsis patients admitted to the hospital by a MICU or an EMT. Data are expressed as absolute value with percentage (\%).

\begin{tabular}{|l|l|l|}
\hline Site of infection & n & Percentage \\
\hline Pulmonary & 77 & $55 \%$ \\
\hline Urinary & 20 & $14 \%$ \\
\hline Digestive & 19 & $13 \%$ \\
\hline Undefined & 10 & $8 \%$ \\
\hline Meningeal & 6 & $4 \%$ \\
\hline Cutaneous & 4 & $3 \%$ \\
\hline Ear Nose Throat & 3 & $2 \%$ \\
\hline Bone & 1 & $1 \%$ \\
\hline
\end{tabular}

Table 3. Univariate analysis of factors associated with mortality at Day 28 in sepsis patients admitted to the hospital by a MICU or an EMT. Data are presented as $p$ value and Odds Ratio (OR) with a $95 \%$ confidence interval $[95 \% \mathrm{CI}]$.

\begin{tabular}{|l|l|l|}
\hline & Univariate analysis & \\
\hline Variables & OR $[\mathbf{9 5} \% \mathbf{C I}]$ & $\boldsymbol{p}$ value \\
\hline Age (years) & $1.03[0.99-1.06]$ & 0.10 \\
\hline Age $>$ 80years & $1.12[0.29-3.69]$ & 0.85 \\
\hline Male & $2.01[0.62-7.75]$ & 0.26 \\
\hline Immunosuppression & $1.46[0.45-5.63]$ & 0.55 \\
\hline Systolic blood pressure $(\mathrm{mmHg})$ & $0.99[0.95-1.01]$ & 0.06 \\
\hline Diastolic blood pressure $(\mathrm{mmHg})$ & $0.98[0.95-1.01]$ & 0.24 \\
\hline Mean blood pressure $(\mathrm{mmHg})$ & $0.98[0.94-1.01]$ & 0.12 \\
\hline Heart rate $($ beats/min) & $1.01[0.98-1.03]$ & 0.59 \\
\hline Pulse oximetry $(\%)$ & $0.99[0.94-1.07]$ & 0.79 \\
\hline Respiratory rate $(\mathrm{moves} / \mathrm{min})$ & $1.06[0.97-1.15]$ & 0.19 \\
\hline GCS & $1.01[0.58-2.67]$ & 0.98 \\
\hline Body temperature $\left({ }^{\circ} \mathrm{C}\right)$ & $0.75[0.51-1.13]$ & 0.14 \\
\hline MICU & $1.47[0.21-6.23]$ & 0.64 \\
\hline qSOFA $>2$ & $1.93[0.59-6.19]$ & 0.26 \\
\hline $\begin{array}{l}\text { GCS: Glasgow coma scale, } \mathrm{MICU}: \\
\text { related organ dysfunction assessment }\end{array}$ & & \\
\hline
\end{tabular}

no impact of prehospital transportation [25], while others described increased mortality of patients transported by EMS [26]. Septic patients transported by EMS died more often as they were more seriously ill on the one hand [26], and transported with less urgent rides than needed on the other hand [27]. However, appropriate EMS transportation shortened the time to initiation of antibiotics and fluid expansion of about 30 to $60 \mathrm{~min}[25,28]$. 
Table 4. Comparison of variables predicting mortality at day 28 of sepsis patients included in the propensity score before and after matching. Values are expressed as number and percentage (\%). Cases correspond to patients admitted to the hospital by a MICU and controls to patients admitted by an EMT.

\begin{tabular}{|c|c|c|c|c|c|c|}
\hline \multirow[b]{2}{*}{ PS covariate } & \multicolumn{3}{|c|}{ Before Matching ( $n=140)$} & \multicolumn{3}{|c|}{ After Matching $(n=32)$} \\
\hline & Cases & Controls & $\mathrm{p}$ value $\left(\mathrm{d}^{*}\right)$ & Cases & Controls & $\mathrm{p}$ value $\left(\mathrm{d}^{*}\right)$ \\
\hline & $\mathrm{n}=16$ & $\mathrm{n}=124$ & & $\mathrm{n}=16$ & $\mathrm{n}=16$ & \\
\hline Age $>80$ years & $6(38 \%)$ & $34(27 \%)$ & 0.21 & $6(38 \%)$ & $10(63 \%)$ & $<10^{-3}$ \\
\hline $\mathrm{qSOFA}>2$ & $7(44 \%)$ & $38(31 \%)$ & 0.27 & $7(44 \%)$ & $7(44 \%)$ & $<10^{-3}$ \\
\hline IS & $11(69 \%)$ & $75(60 \%)$ & 0.17 & $11(69 \%)$ & $11(69 \%)$ & $<10^{-3}$ \\
\hline
\end{tabular}

PS: propensity score, qSOFA: quick sepsis-related organ dysfunction assessment score, IS:Immunosuppression.

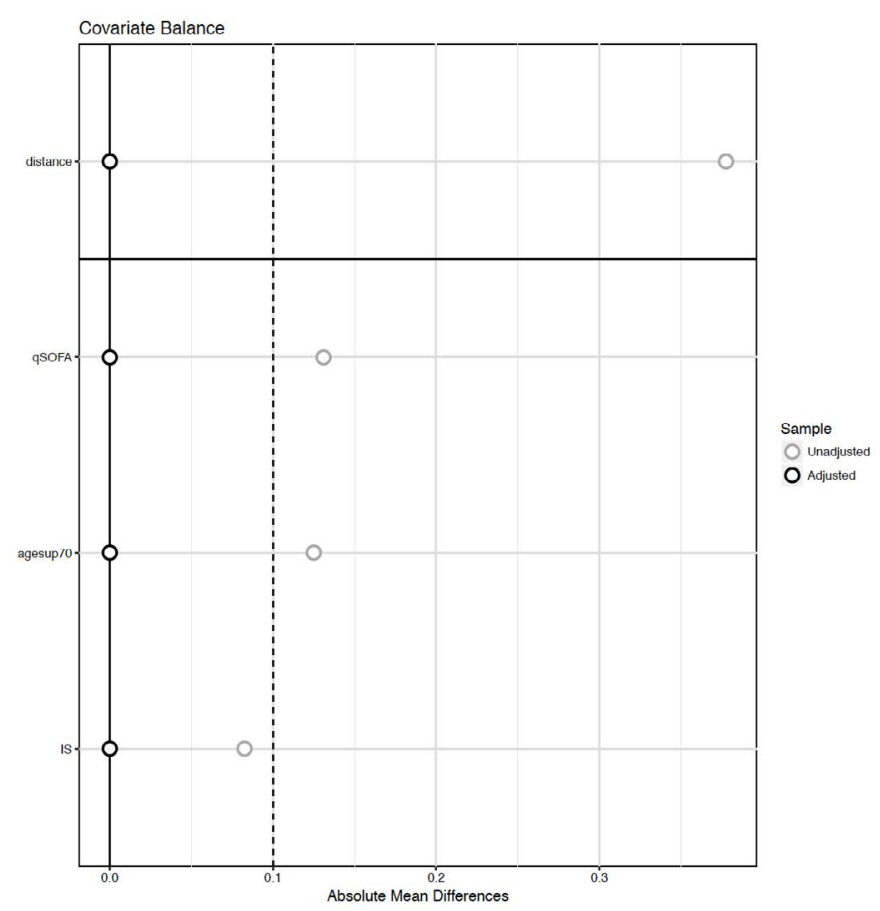

Figure 2. Standard mean deviation between cases and controls after propensity score matching. Cases correspond to patients admitted to the hospital by a MICU and controls to patients admitted by an EMT.

The time lapse between the diagnosis of sepsis and the initiation of treatments is a well-proven prognosis factor affecting patients' outcome in sepsis [29-32]. Consequently, improvement of the management of sepsis in the survival chain, in analogy to cardiac arrest management, aimed at reducing the time-to-treatment [30]. Indeed, early ICU admission significantly improved the prognosis of patients with septic shock [33]. However, no defined strategy is currently used for the management of prehospital sepsis patients, on the contrary to the clear guidelines on acute coronary syndromes [34,35]. Should critical patients be admitted to the ICU directly or should they first transit through the ED? Should they be cared for in the prehospital setting directly by a MICU or might an EMT be sufficient? The absence of relevant tools for prehospital triage of septic patients underlines the complexity of the issue. Actually, no vital sign is enough for decisionmaking. Additionally, biological values are time-consuming and hard to get in this context. These difficulties account for the differences between studies on the benefit of the bundle of care strategy [29,30,32]. Anyhow, the bundle of care concept describes key points for the global management of septic patients that must be performed within a time scale of 3 hours, to significantly decrease mortality [29].

\section{Strengths and Limitations}

Some limitations restrict the interpretation of our results. First, this is a retrospective and single centre study. Consequently, our results may not be extrapolated to other populations, medical institutions or countries. Actually, studies on prehospital transportation mode compared EMS to non-EMS without including MICUs [25,27,28]. Moreover, the quality of care provided by EMS significantly differed between hospitals and countries. In a lot of countries, paramedical teams have an insufficient knowledge concerning sepsis with an under evaluation of hypothermia [36] and poor recognition of sepsis [37]. In parallel, in some countries, EMS teams have the ability to recognize sepsis and thus reduce the time to initiation of optimal therapies. Second, the sample size is small, decreasing the power of the study. Third, a sorting bias may exist as data were retrospectively collected from the SAMU regulation centre call recorded phone calls and ICU or ED medical reports. At last but not least, we could not investigate the effect of prehospital antibiotherapy as no patients received antibiotics prior to hospital admission. Similarly, we could not study hemodynamic optimization, as data lacked from the SAMU reports. Importantly, prehospital transportation in Paris is very efficient and the time required to transfer a patient to the hospital is less likely to delay the time to treatment or interfere with mortality. Anyhow, antibiotics is a confounding factor and would have interfered with our results

Despite these limitations, we observed a positive impact of the intervention of prehospital MICU on mortality of patients with sepsis at day 28 initially cared for in the prehospital setting. Still larger cohorts are needed to confirm these preliminary data and to provide a causal link between mortality and prehospital MICU intervention.

\section{Conclusion}

We described an association between prehospital mobile intensive care unit intervention and mortality at day 28 in sepsis patients. MICU transportation of out-of-hospital sepsis patients was associated with a relative risk reduction of $60 \%$ of death at day 28 .

These results underline the need to optimize prehospital management of sepsis patients starting from patients' transportation to hospital admission. Larger studies are needed to confirm the impact of MICU intervention on mortality of patients with sepsis initially cared for in the prehospital setting.

\section{References}

1. Fleischmann C, Scherag A, Adhikari NK, Hartog CS, Tsaganos T, et al. (2016) Assessment of Global Incidence and Mortality of Hospital-treated Sepsis. Current Estimates and Limitations. Am J Respir Crit Care Med 193: 259-272. [Crossref]

2. Gaieski DF, Edwards JM, Kallan MJ, Carr BG (2013) Benchmarking the incidence and mortality of severe sepsis in the United States. Crit Care Med 41: 1167-1174. [Crossref]

3. Epstein L, Dantes R, Magill S, Fiore A (2016) Varying Estimates of Sepsis Mortality Using Death Certificates and Administrative Codes--United States, 1999-2014. MMWR Morb Mortal Wkly Rep 65: 342-345. [Crossref]

4. Annane D, Aegerter P, Jars-Guincestre MC, Guidet B, Network CU-R (2003) Current epidemiology of septic shock: the CUB-Rea Network. Am J Respir Crit Care Med 168 165-172. [Crossref] 
5. Singer M, Deutschman CS, Seymour CW, Shankar-Hari M, Annane D, et al. (2016) The Third International Consensus Definitions for Sepsis and Septic Shock (Sepsis-3). JAMA 315: 801-810. [Crossref]

6. Delaney A, Peake SL, Bellomo R, Cameron P, Holdgate A, et al. (2013) Australasian Resuscitation In Sepsis Evaluation trial statistical analysis plan. Emerg Med Australas 25: 406-415.

7. Delaney AP, Peake SL, Bellomo R, Cameron P, Holdgate A, et al. (2013) The Australasian Resuscitation in Sepsis Evaluation (ARISE) trial statistical analysis plan. Crit Care Resusc 15: 162-171.

8. Pro CI, Yealy DM, Kellum JA, Huang DT, Barnato AE, et al. (2014) A randomized trial of protocol-based care for early septic shock. $N$ Engl J Med 370: 1683-1693. [Crossref]

9. Adnet F, Lapostolle F (2004) International EMS systems: France. Resuscitation 63: 7-9. [Crossref]

10. Barbara P, Graziano C, Caputo W, Litvak I, Battinelli D, et al. (2018) The quick sequential organ failure assessment (qSOFA) identifies septic patients in the out-ofhospital setting. Am J Emerg Med. [Crossref]

11. Jouffroy R, Saade A, Carpentier A, Ellouze S, Philippe P, et al. (2018) Triage of Septic Patients Using qSOFA Criteria at the SAMU Regulation: A Retrospective Analysis. Prehosp Emerg Care 22: 84-90. [Crossref]

12. Jouffroy R, Saade A, Ellouze S, Carpentier A, Michaloux M, et al. (2018) Prehospital triage of septic patients at the SAMU regulation: Comparison of qSOFA, MRST, MEWS and PRESEP scores. Am J Emerg Med 36: 820-824. [Crossref]

13. Tusgul S, Carron PN, Yersin B, Calandra T, Dami F (2017) Low sensitivity of qSOFA, SIRS criteria and sepsis definition to identify infected patients at risk of complication in the prehospital setting and at the emergency department triage. Scand J Trauma Resusc Emerg Med 25: 108. [Crossref]

14. Seymour CW, Liu VX, Iwashyna TJ, Brunkhorst FM, Rea TD, et al. (2016) Assessment of Clinical Criteria for Sepsis: For the Third International Consensus Definitions for Sepsis and Septic Shock (Sepsis-3). JAMA 315: 762-774.

15. Bone RC, Sibbald WJ, Sprung CL (1992) The ACCP-SCCM consensus conference on sepsis and organ failure. Chest 101: 1481-1483.

16. Pottecher T, Calvat S, Dupont H, Durand-Gasselin J, Gerbeaux P, et al. (2006) Haemodynamic management of severe sepsis: recommendations of the French Intensive Care Societies (SFAR/SRLF) Consensus Conference, 13 October 2005, Paris, France. Crit Care 10: 311. [Crossref]

17. Gearing RE, Mian IA, Barber J, Ickowicz A (2006) A methodology for conducting retrospective chart review research in child and adolescent psychiatry. $J$ Can Acad Child Adolesc Psychiatry 15: 126-134.

18. Telion C, Greffet A, Rozenberg A, Lejay M, Janniere D, et al. (2000) Is the direct admission to the recovery service or to the intensive care unit of patients cared for by the Smur system justified?. Ann Fr Anesth Reanim 19: 654-661.

19. Austin PC (2011) An Introduction to Propensity Score Methods for Reducing the Effects of Confounding in Observational Studies. Multivariate Behav Res 46: 399-424. [Crossref]

20. Martin GS, Mannino DM, Moss M (2006) The effect of age on the development and outcome of adult sepsis. Crit Care Med 34: 15-21.

21. Rowe T, Araujo KL, Van Ness PH, Pisani MA, Juthani-Mehta M (2016) Outcomes of Older Adults With Sepsis at Admission to an Intensive Care Unit. Open Forum Infect Dis 3: ofw010. [Crossref]
22. Tolsma V, Schwebel C, Azoulay E, Darmon M, Souweine B, et al. (2014) Sepsis severe or septic shock: outcome according to immune status and immunodeficiency profile. Chest 146: 1205-1213. [Crossref]

23. Austin PC (2008) Goodness-of-fit diagnostics for the propensity score model when estimating treatment effects using covariate adjustment with the propensity score. Pharmacoepidemiol Drug Saf 17: 1202-1217. [Crossref]

24. Strauch U, Bergmans DC, Winkens B, Roekaerts PM (2015) Short-term outcomes and mortality after interhospital intensive care transportation: an observational prospective cohort study of 368 consecutive transports with a mobile intensive care unit. BMJ Open 5: e006801.

25. Band RA, Gaieski DF, Hylton JH, Shofer FS, Goyal M, et al. (2011) Arriving by emergency medical services improves time to treatment endpoints for patients with severe sepsis or septic shock. Acad Emerg Med 18: 934-940. [Crossref]

26. Pedersen PB, Henriksen DP, Mikkelsen S, Lassen AT (2017) Dispatch and prehospita transport for acute septic patients: an observational study. Scand J Trauma Resusc Emerg Med 25: 51. [Crossref]

27. Groenewoudt M, Roest AA, Leijten FM, Stassen PM (2014) Septic patients arriving with emergency medical services: a seriously ill population. Eur J Emerg Med 21: 330-335. [Crossref]

28. Studnek JR, Artho MR, Garner CL, Jones AE (2012) The impact of emergency medical services on the ED care of severe sepsis. Am J Emerg Med 30: 51-56. [Crossref]

29. Leisman DE, Doerfler ME, Ward MF, Masick KD, Wie BJ, et al. (2017) Survival Benefit and Cost Savings From Compliance With a Simplified 3-Hour Sepsis Bundle in a Series of Prospective, Multisite, Observational Cohorts. Crit Care Med 45: 395 406. [Crossref]

30. Peltan ID, Mitchell KH, Rudd KE, Mann BA, Carlbom DJ, et al. (2017) Physician Variation in Time to Antimicrobial Treatment for Septic Patients Presenting to the Emergency Department. Crit Care Med 45: 1011-1018. [Crossref]

31. Rivers E, Nguyen B, Havstad S, Ressler J, Muzzin A, et al. (2001) Early goal-directed therapy in the treatment of severe sepsis and septic shock. N Engl J Med 345: 13681377.

32. Seymour CW, Gesten F, Prescott HC, Friedrich ME, Iwashyna TJ, et al. (2017) Time to Treatment and Mortality during Mandated Emergency Care for Sepsis. $N$ Engl J Med 376: 2235-2244.

33. Surat T, Viarasilpa T, Permpikul C (2014) The impact of intensive care unit admissions following early resuscitation on the outcome of patients with severe sepsis and septic shock. J Med Assoc Thai 97: S69-76.

34. Steg PG, Cambou JP, Goldstein P, Durand E, Sauval P, et al. (2006) Bypassing the emergency room reduces delays and mortality in ST elevation myocardial infarction: the USIC 2000 registry. Heart 92: 1378-1383. [Crossref]

35. Wijns W, Kolh P, Danchin N (2010) Task Force on Myocardial Revascularization of the European Society of C, the European Association for Cardio-Thoracic S, European Association for Percutaneous Cardiovascular I. Guidelines on myocardial revascularization. Eur Heart J 31: 2501-2555.

36. Shime N (2015) A Survey of the Competency of Ambulance Service Personnel in the Diagnosis and Management of Sepsis. J Emerg Med 49: 147-151.

37. Smyth MA, Brace-McDonnell SJ, Perkins GD (2016) Identification of adults with sepsis in the prehospital environment: a systematic review. BMJ Open 6: 011218.

Copyright: (C2018 Jouffroy R. This is an open-access article distributed under the terms of the Creative Commons Attribution License, which permits unrestricted use, distribution, and reproduction in any medium, provided the original author and source are credited. 